\title{
POTENTIAL OF NON-CALIBRATED UAV-BASED RGB IMAGERY FOR FORAGE MONITORING: CASE STUDY AT THE RENGEN LONG-TERM GRASSLAND EXPERIMENT (RGE), GERMANY
}

\author{
G. Bareth ${ }^{1 *}$, U. Lussem ${ }^{1}$, J. Menne ${ }^{1}$, J. Hollberg ${ }^{2}$, J. Schellberg ${ }^{2}$ \\ ${ }^{1}$ GIS \& RS Group, Institute of Geography, University of Cologne, Germany - \\ (g.bareth, ulrike.lussem, jannis.menne)@uni-koeln.de \\ ${ }^{2}$ Institute of Crop Production (INRES), Bonn University, Germany (j.schellberg@uni-bonn.de)
}

UAVg - Geospatial Week 2019

KEY WORDS: UAS, RPAS, RGB, vegetation index, plant height, grassland, biomass, rising plate meter

\begin{abstract}
:
Forage monitoring in grassland is an important task to support management decisions. Spatial data on (i) yield,(ii) quality, and (iii) floristic composition are of interest. The spatio-temporal variability in grasslands is significant and requires fast and low-cost methods for data delivery. Therefore, the overarching aim of this contribution is the investigation of low-cost and non-calibrated UAV-derived RGB imagery for forage monitoring. Study area is the Rengen Grassland Experiment (RGE) in Germany which is a long-term field experiment since 1941. Due to the experiment layout, destructive biomass sampling during the growing period was not possible. Hence, non-destructive Rising Plate Meter (RPM) measurements, which are a common method to estimate biomass in grasslands, were carried out. UAV campaigns with a Canon Powershot 110 mounted on a DJI Phantom 2 were conducted in the first growing season in 2014. From the RGB imagery, the RGB vegetation index (RGBVI) and the Grassland Index (GrassI) introduced by Bendig et al. (2015) and Bareth et al. (2015), respectively, were computed. The RGBVI and the GrassI perform very well against the RPM measurements resulting in $\mathrm{R}^{2}$ of 0.84 and 0.9 , respectively. These results indicate the potential of low-cost UAV methods for grassland monitoring and correspond well to the studies of Viljanen et al. (2018) and Näsi et al. (2018).
\end{abstract}

\section{INTRODUCTION}

Since decades, the non-destructive monitoring of managed grassland ecosystems is in the focus of research activities (i) to optimize management and (ii) to reduce $\mathrm{N}$ losses like nitrate leaching. Therefore, spatial information on growth patterns are demanded for site-specific improvement of nutrient management (Hejcman et al., 2010). Besides, the monitoring of spatio-temporal forage mass production and quality is of key interest in meadows and pastures (Catchpole and Wheeler, 1992). A challenge in non-destructive grassland monitoring is the spatio-temporal heterogeneity of growth patterns and floristic composition which requires high spatio-temoporal data acquisition to capture the related patterns (Schellberg et al., 1999).

In this context, Unmanned Aerial Vehicles (UAVs) provide the necessary flexibility for the demanded data acquisition (Colomina and Molina, 2014). Daily weekly or bi-weekly campaigns are possible and affordable (Bareth and Schellberg, 2018). With UAV-based data acquisition, it is possible to acquire spectral and structural data (Näsi et al., 2018; Viljanen et al., 2018). Spectral data are captured with miniaturized multi- or hyperspectral cameras for computing vegetation indices. Structural data are usually derived from $2.5 \mathrm{D}$ or $3 \mathrm{D}$ data which are used to compute plant height and plant density. The latter concept was introduced by Hoffmeister et al. (2010) using laser scanning data and by Bendig et al. (2013) for UAVbased RGB data.
The objectives of this study are (i) investigating the potential of low-cost UAVs for forage monitoring, (ii) evaluating the potential of vegetation indices (VIs) of the VIS domain, the RGBVI, and (iii) analysing the potential of the combined structural/spectral Grassland Index (GrassI) for biomass monitoring. The latter was introcuded by Bareth et al. (2015) and was investigated with promising results by Näsi et al. (2018) and Viljanen et al. (2018).

\section{METHODS AND DATA}

In this contribution, we present a study which was conducted at the Rengen Grassland Experiment (RGE) in Germany which is a long-term field experiment established in 1941(Schellberg et al. 1999) The RGE is located in West Germany in the Eifel near the city of Daun. The experiment layout is shown in Fig.1. It is a fertilizer experiments with five different nutrient treatments and five repetitions covering $3 * 5 \mathrm{~m}$ plots. The longterm management developed distinct grassland ecosystems (Hejcman et al., 2010). This is visible in the different plot colours shown in Fig.1. Brighter colours indicate reduced nutrient provision. A detailed description of the experiment layout is given by Schellberg et al. (1999).

More information are accessible at via http://www.lap.unibonn.de/forschung/forschungsprojekte/DDV\%20Rengen.

\footnotetext{
* Corresponding author
} 


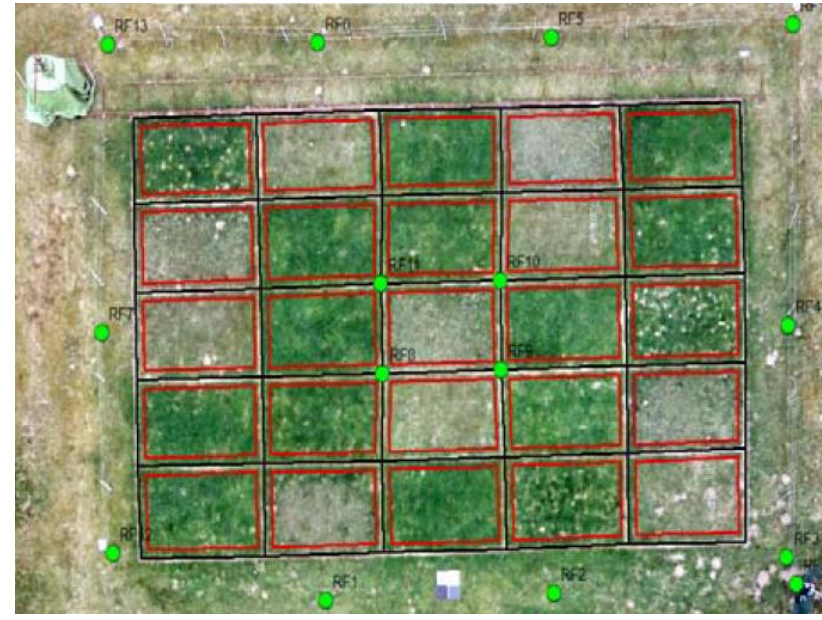

Figure 1. The RGE experiment (Bareth et al. 2015)

For the non-destructive UAV-based monitoring, a DJI Phantom 2 was purchased and a Canon Powershot 110 digital compact camera was mounted using a fixed camera mount. The system is shown in Fig.2. For data acquisition, a manual flight pattern in approx. $20 \mathrm{~m}$ above ground was flown. Continous image acquisition was realized with a CHDK software installed on the camera's SD card. Every second an image was taken. The spatial resolution of the images is approx. $1 \mathrm{~cm}$.

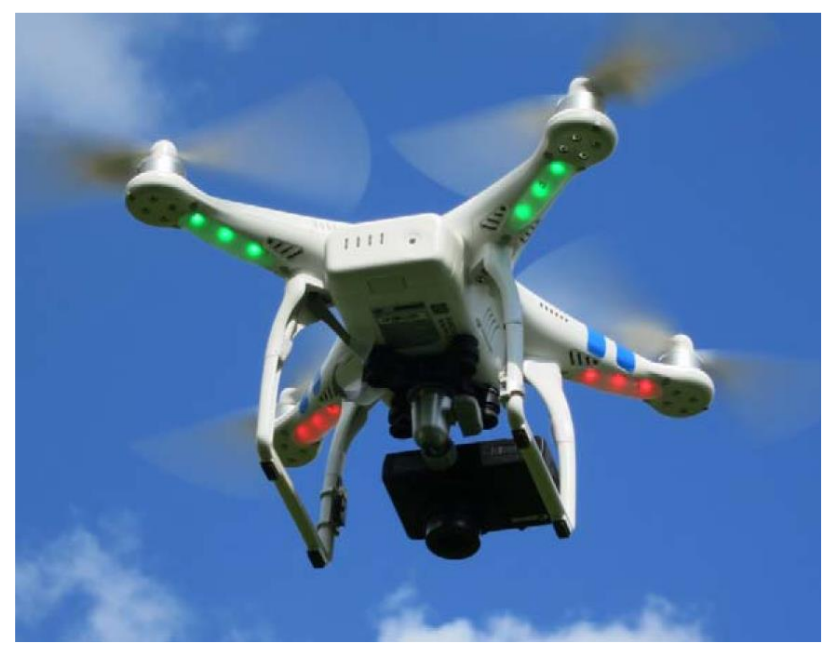

Figure 2. DJI Phantom 2 with mounted Canon Powershot 110 (Bareth et al. 2015)

Compressed sward height was measured manually in the field experiment using a Rising Plate Meter (RPM). RPMs are an established method to non-destructively estimate biomass from the compress sward height data which represents a height/density information (Catchpole and Wheeler, 1992). UAV-derived sward height was computed using the crop surface model (CSM) approach introduced by Hoffmeister et al. (2010) for laserscanning data and by Bendig et al. (2013) for UAV-based image acquisition. CSMs were computed with the photogrammetric Software PhotoScan which is using Structure from Motion (SfM) and Multi-view Stereopsis (MVS) techniques. In Fig.3 the CSM approach is shown. CSMs are Digital Surface Models (DSMs) of a crop canopy in ultra-high spatial resolution of $<2 \mathrm{~cm}$ (Bendig et al. 2013).
Subtracting an UAV-derived Digital Elevation Model (DEM) from a given CSM results in pixelwise crop height data. By subtracting a CSM of an early growing stage from a CSM of the later season, even plant growth rates can be determined. Several studies proofed for crops that CSM-derived plant height data is a robust estimator for crop biomass (Bendig et al., 2015; Tilly et al. 2015). The approach was successfully transferred by Bareth et al. (2015) to monitor grasslands and the findings by Zhang et al. (2018) support the potential for grassland monitoring.

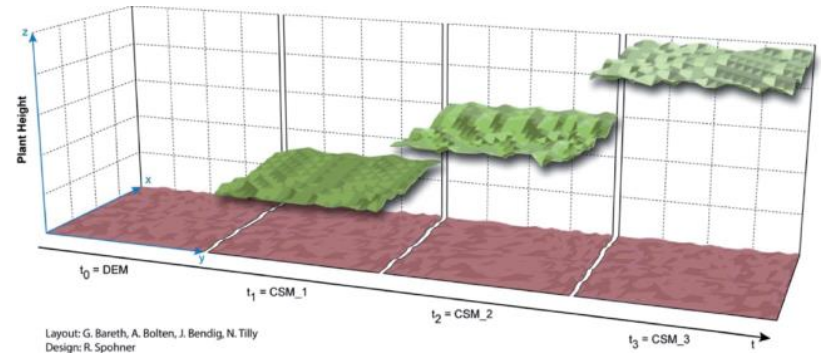

Figure 3. UAV-based plant height analysis with multi-temporal crop surface models (CSMs) (Bendig et al. 2013)

The non-calibrated, UAV-derived RGB imagery was used to compute a VI using the VIS domain. Bendig et al (2015) introduced a VI using RGB bands, the RGBVI. Bareth et al. (2015) applied the RGBVI with promising results on grasslands. The RGBVI is a NDVI-based VI:

$$
R G B V I=\left(G^{*} G-B^{*} R\right) /\left(G^{*} G+B^{*} R\right)
$$

A second index used in this study is the Grassland Index (GrassI) which was introduced by Bareth et al. (2015). The Grass I combines UAV-derived sward height (CSM-SH) in $\mathrm{cm}$ with RGBVI data:

$$
\text { Grass } I=C S M-S H+R G B V I
$$

Finally, forage mass was destructively determined after the first growth in early July 2014. Additional destructive biomass sampling is not allowed in the RGE due to its long-term character. The latter is an important issue because in this study only data are considered before lodging occurred. Therefore, a direct non-destructive data acquisition having no lodging before biomass sampling was not possible.

\section{RESULTS}

In this contribution, we present regression analyses for the first growth in 2014 using the RPM measurements of compressed sward height (RPM-SH) as a representative for biomass. Per plot 10 RPM measurements were conducted and averaged. The UAV-derived CSM and VI data were also averaged per plot using zonal statistics. Spatial resolution of the CSM data is $0.02 \mathrm{~m}$ and of the VI data is $0.01 \mathrm{~m}$. As it is shown in Fig. 1 an inner buffer of $0.3 \mathrm{~m}$ was applied to reduce plot border effects in the plot data. UAV and RPM data acquisition occurred five times from $16^{\text {th }}$ April 2019 to $28^{\text {th }}$ May 2019. The five repetition of each management are averaged resulting in five data pairs per campaign giving a total $n$ of 25 . 
In Fig.4, averaged RPM-SH is plotted against averaged RGBVI data per management plot. Even so, the computation of the RGBVI is based on uncalibrated spectral data, the relationship is high having a $\mathrm{R}^{2}$ of 0.84 .

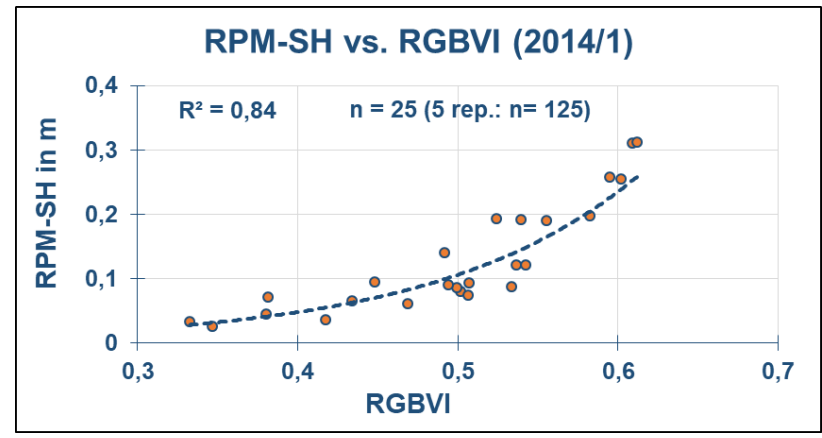

Figure 4. Relationship of RPM-SH and RGBVI data

A similar relationship is given when plotting RPM-SH against UAV-derived CSM-SH data. CSM-SH was UAV-derived according to the CSM approach by Bendig et al. (2013) and is performing well against the manual RPM-SH measurements. The $\mathrm{R}^{2}$ results in 0.82 .

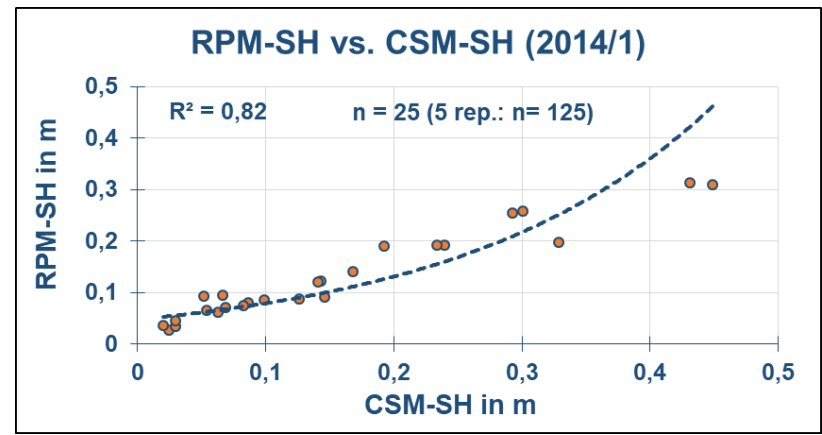

Figure 5. Relationship of RPM-SH and CSM-SH data

The combination of CSM-SH and RGBVI data is considered in the GrassI according to Bareth et al. (2015) as the sum of both. In Fig.6 the correlation with the RPM-SH data is very high achieving a $\mathrm{R}^{2}$ of 0.9 .

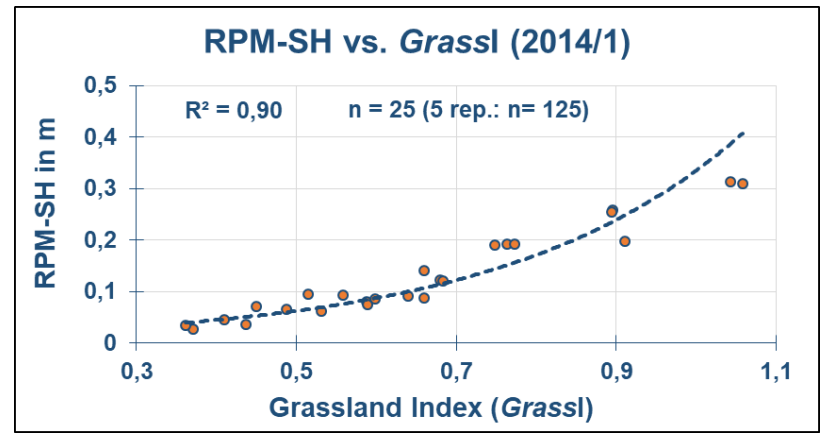

Figure 6. Relationship of RPM-SH and GrassI data

Finally, the RPM-SH measurements just before destructive biomass sampling (early July 2014) are plotted against dry biomass in Fig.7. Even so the number of $\mathrm{n}$ is very low $(\mathrm{n}=5)$, the described relationship having a $\mathrm{R}^{2}$ of 0.75 is in the lower range of reported correlations of RPM measurements for biomass estimation. However, the potential of RPM measurements to serve as a biomass predictor seems to be also true for the RGE.

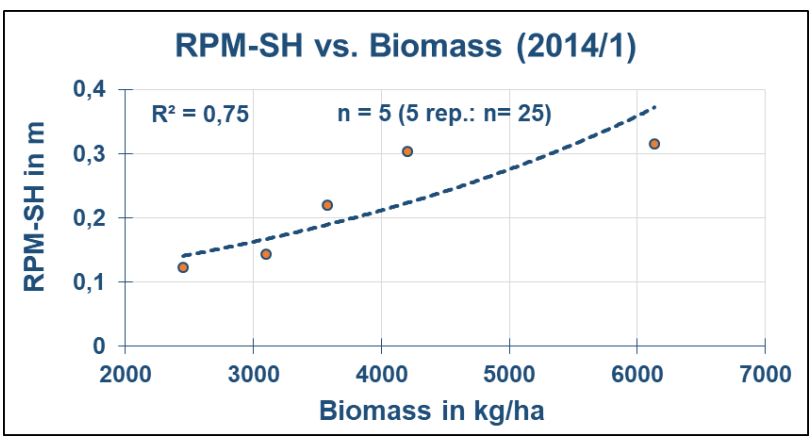

Figure 7. Relationship of RPM-SH and dry biomass data

\section{DISCUSSION \& CONCLUSIONS}

The findings of this study indicate a promising potential of low-cost UAV-based monitoring of forage mass in managed grasslands. CSM-SH, RGBVI, and GrassI show high relationships with $\mathrm{R}^{2}$ of $0.82,0.84$, and 0.9 , respectively, with RPM-SH measurements. The potential of UAV-derived sward height (CSM-SH) as a predictor for RPM-SH for forage mass seems to be unexploited. The same seems to be true for combined spectral and structural analysis like the GrassI. These findings correspond very well to the findings of Grüner et al. (2019), Viljanen et al. (2018), and Moeckel et al. (2017). Grüner et al. (2019) describes CSM-SH relationships with canopy height measurements using a ruler between $\mathrm{R}^{2}$ of 0.56 and 0.7 , and with dry biomass between $\mathrm{R}^{2}$ of 0.64 and 0.75 . Viljanen et al. (2018) investigated the performance of combined spectral and structural data analysis. The GrassI performed second best in this study and was only slightly outperformed by a similar approach adding CSM-SH and the Excess Green Index (ExG). Combining CSM-SH and VIs performed best in a random forest (RF) and multiple linear regression (MLR) analysis (Viljanen et al., 2018). Fricke et al. (2011) and Moeckel et al (2017) are using successfully ultrasonic proximal sensors for grassland monitoring and investigated the combined analysis in grazing experiments which were only partly successful and seem to have limitations in grassland monitoring of disturbed canopies.

However, the results of the presented study using a low-cost UAV approach for forage monitoring in managed grasslands seems to have a potential to be introduced as robust predictors in such systems. Viljanen et al. (2018) conclude similarly: "These results were extremely promising, showing that the proposed multispectral photogrammetric approach can provide accurate biomass estimates of grass swards, and could be developed as a low-cost tool for practical farming applications."

\section{ACKNOWLEDGEMENTS}

The BMBF-funded project GreenGrass (FKZ: 031B0734F) covers the participation at the UAVg. 


\section{REFERENCES}

Bareth, G, Schellberg, J, 2018. Replacing manual rising plate meter measurements with low-cost UAV-derived sward height data in grasslands for spatial monitoring. PFG, 86(3-4), 157168. doi: 10.1007/s41064-018-0055-2

Bareth G, Bolten A, Hollberg J, Aasen H, Burkhart A, Schellberg J, 2015. Feasibility study of using non-calibrated UAV-based RGB imagery for grassland monitoring: case study at the Rengen Long-term Grassland Experiment (RGE), Germany. Proc. DGPF annual conference'15, Cologne, Germany, 55-62. https://dgpf.de/src/tagung/jt2015/ proceedings/papers/07_DGPF2015_Bareth_et_al.pdf

Bendig J, Yu K, Aasen H, Bolten A, Bennertz S, Broscheit J, Gnyp ML, Bareth G, 2015. Combining UAV-based plant height from crop surface models, visible, and near infrared vegetation indices for biomass monitoring in barley. Int J Appl Earth Obs Geoinform., 39, 79-87. doi: 10.1016/j.jag.2015.02.012

Bendig J, Bolten A, Bareth G, 2013. UAV-based imaging for multi-temporal, very high resolution crop surface models to monitor crop growth variability. $P F G$ 2013(6), 551-562. doi: 10.1127/1432-8364/2013/0200

Catchpole WR, Wheeler CJ, 1992. Estimating plant biomass: a review of techniques. Aust $J$ Ecol, 17, 121-131. https://doi.org/10.1111/j.1442-9993.1992.tb00790.x

Colomina I, Molina P, 2014. Unmanned aerial systems for photogrammetry and remote sensing: a review. ISPRS J Photogramm. Remote Sens., 92, 79-97. doi: 10.1016/j.isprsjprs.2014.02.013

Fricke T, Richter F, Wachendorf M, 2011. Assessment of forage mass from grassland swards by height measurement using an ultrasonic sensor. Comput Electron Agric., 79, 142 152. doi: 10.1016/j.compag.2011.09.005

Grüner, E, Astor, T, Wachendorf, M, 2019. Biomass prediction of heterogeneous temperate grasslands using an SfM approach based on UAV imaging. Agronomy, 9(2), 54. doi: 10.3390/agronomy 9020054

Hejcman M, Szaková J, Schellberg J, Tlustoš P, 2010. The Rengen grassland experiment: relationship between soil and biomass chemical properties, amount of elements applied, and their uptake. Plant Soil, 333, 163-179. doi: 10.1007/s11104010-0332-3

Hoffmeister D, Bolten A, Curdt C, Waldhoff G, Bareth G, 2010. High-resolution crop surface models (CSM) and crop volume models (CVM) on field level by terrestrial laser scanning. In: Guo H, Wang C (eds) SPIE sixth international symposium on digital earth: models, algorithms, and virtual reality, Beijing, China, 78400E-78400E6. doi: $10.1117 / 12.872315$

Moeckel T, Safari H, Reddersen B, Fricke T, Wachendorf M, 2017. Fusion of ultrasonic and spectral sensor data for improving the estimation of biomass in grasslands with heterogeneous sward structure. Remote Sens., 9(1), 98. doi: $10.3390 / \mathrm{rs} 9010098$

Näsi R, Viljanen N, Kaivosoja J, Alhonoja K, Hakala T, Markelin L, Honkavaara E, 2018. Estimating biomass and nitrogen amount of barley and grass using UAV and aircraft based spectral and photogrammetric 3D features. Remote Sens., 10(7), 1082. doi: 10.3390/rs10071082

Schellberg J, Möseler BM, Kühbauch W, Rademacher I, 1999. Long-term effects of fertilizer on soil nutrient concentration, yield, forage quality and floristic composition of a hay meadow in the Eifel Mountains, Germany. Grass Forage Sci., 54, 195207. doi: 10.1046/j.1365-2494.1999.00166.x

Viljanen N, Honkavaara E, Näsi R, Hakala T, Niemeläinen O, Kaivosoja J, 2018. A novel machine learning method for estimating biomass of grass swards using a photogrammetric canopy height model, images and vegetation indices captured by a drone. Agriculture, 8(5), 70. doi: 10.3390/agriculture 8050070

Zhang H, Sun Y, Chang L, Qin Y, Chen J, Qin Y, Du J, Yi S, Wang Y, 2018. Estimation of grassland canopy height and aboveground biomass at the quadrat scale using unmanned aerial vehicle. Remote Sens., 10(6), 851. doi: $10.3390 / \mathrm{rs} 10060851$ 